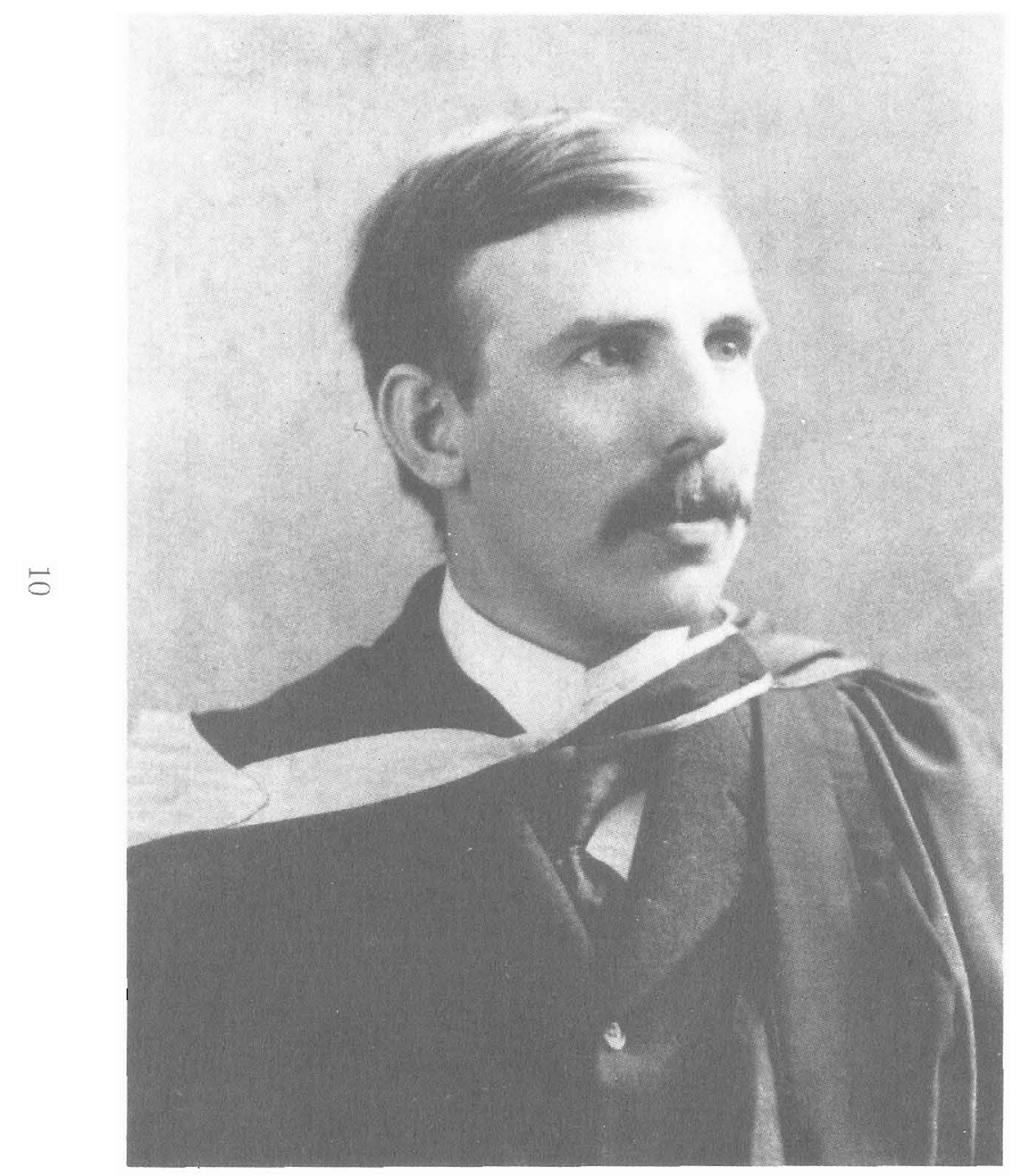

Figure 1. Ernest Rutherford as a young man, c. 1900.

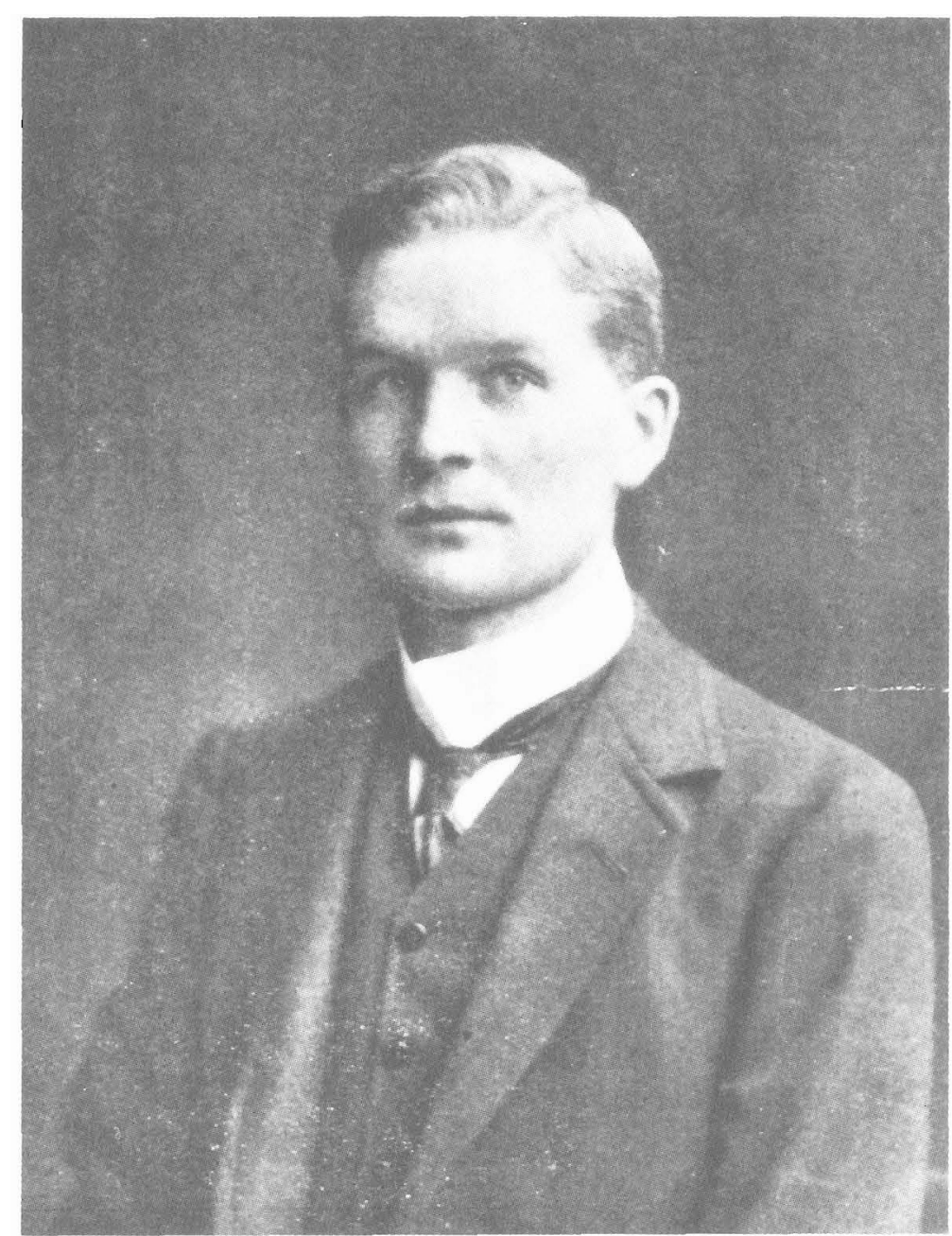

Figure 3. Frederick Soddy 


\section{McGill's Nobel Laureate: The Rutherford Centenary}

\section{by Montague Cohen}

1998 marks the centenary of the appointment of Ernest Rutherford as Macdonald Professor of Physics at McGill University. This article discusses Rutherford's reasons for accepting the post in Canada, and summarizes his research achievements during his nine-year tenure, including the enunciation (with Frederick Soddy) of the transformation theory of radioactivity.

1998 marque le centenaire de la nomination d'Ernest Rutherford à la chaire Macdonald de physique à l'Université McGill. Cet article expose les raisons qui ont poussé Rutherford à accepter ce poste au Canada et donne un aperçu des recherches qu'il y a menées pendant neuf ans, notamment la formulation (avec Frederick Soddy) de la théorie des transformations radioactives.

\section{Arrival in Montreal}

On September 22, 1898, a young New Zealand scientist (Fig. 1) landed in Montreal, after a slow and stormy voyage across the Atlantic and along the St. Lawrence River. Ernest Rutherford, the newlyappointed Macdonald Professor of Physics at McGill University, was ready and anxious to continue the research in the new field of "radioactivity" which he had begun as an 1851 Science Scholar at Cambridge University.

Why did Rutherford agree to come to McGill? ("Agree" rather than "apply" because the post had been offered to him without a prior application on his part.) Nowadays this question would be considered strange, even insulting, but in 1898 it posed a real problem for a scientist in the early stage of his career. The centre of science at that time was firmly in Europe, including the U.K., and communication was such that it was a definite advantage for a young scientist to work at or near the centre.

From Rutherford's point of view the McGill post offered several important advantages. Firstly, he be- came a Full Professor at the age of 27, a promotion virtually impossible in the U.K. (His mentor, J.J. Thomson, for example, was 37 when he was appointed Cavendish Professor of Physics at Cambridge.) Secondly, the annual salary of $£ 500$ (or $\$ 2,500$ ) was very good, and Rutherford needed the money since he was engaged to be married. Thirdly, the Physics Laboratory at McGill - it was not yet designated a Department - was housed in a new building, opened in 1893, thanks to the generosity of the tobacco millionaire William Macdonald, and was reputed to be one of the finest science buildings in the world, perhaps even the finest. Furthermore, the building was generously equipped and Macdonald was willing to finance the purchase of further equipment as required - an undertaking he did, in fact, fulfil. Finally, the post was essentially a Research Professorship and this was what Rutherford wanted.

The Chairman of the McGill Physics Laboratory, Professor John Cox, was an excellent teacher but an indifferent researcher: he was happy to bear the brunt of the teaching load. ${ }^{1}$ Nevertheless it is clear

\footnotetext{
${ }^{1}$ At this time very few Canadian students attended physics courses in order to become professional pbysicists. However,
} 
Figure 2. Exponential decrease in radioactive emission measured by Rutherford in $1900^{1}$ (Curve A), accompanied by corresponding growth in the decay product ( Curve B ).
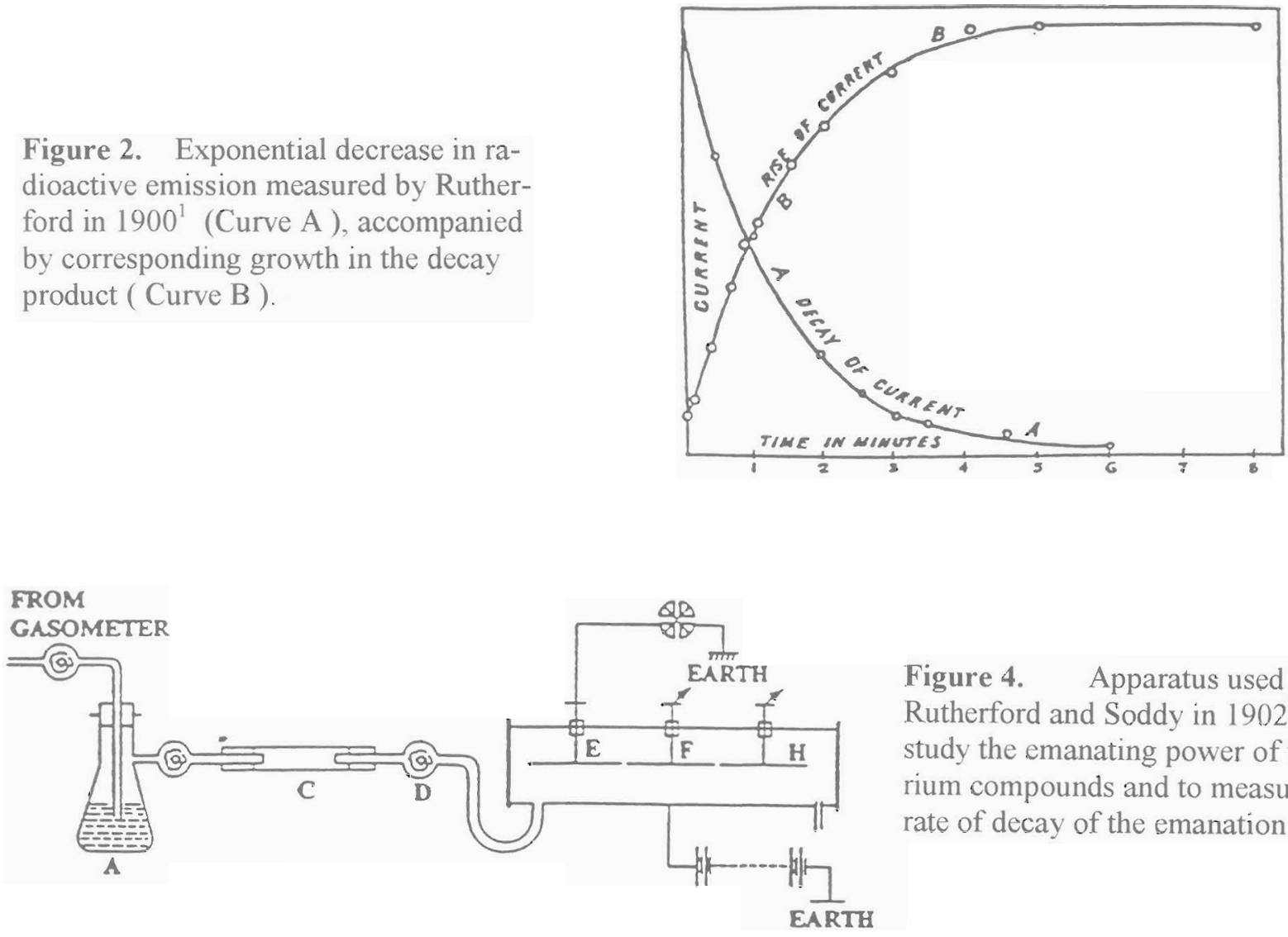

Figure 4. Apparatus used by Rutherford and Soddy in $1902^{2}$ to study the emanating power of thorium compounds and to measure the rate of decay of the emanation

Figure 5. Apparatus used Rutherford in $1903^{3}$ to prove that $\alpha$ - rays are positively charged particles.

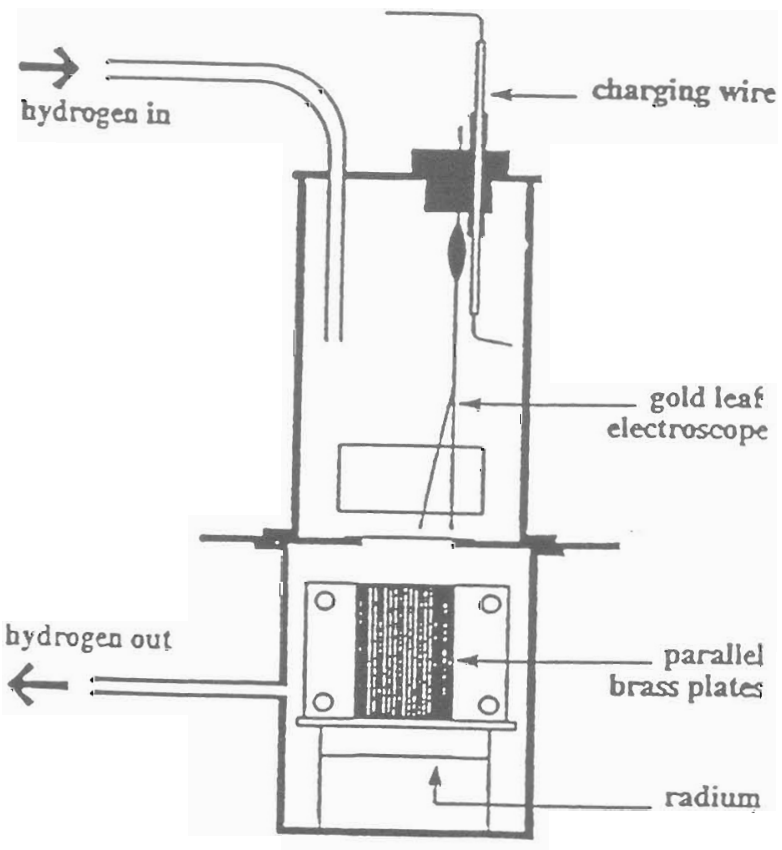


from Rutherford's letters to his parents and fiancée that he did not intend to stay at McGill for as long as nine years: three or four years certainly, perhaps even five, but definitely not nine!

\section{Research at McGill}

Rutherford's research at McGill may conveniently be divided into four periods, which will be discussed briefly as follows:

\section{$1898-1902$}

Rutherford elucidated the basic properties of radioactivity, including the emission during the radioactive process of two different kinds of radiation, which he termed alpha and beta rays. (There is good evidence that Rutherford was aware of the emission of a third radiation, the gamma rays, but the formal discovery of this radiation is usually attributed to the French scientist Paul Villard in 1900.) Rutherford showed that radioactive emission by a given element decreases exponentially with time, while the decay product increases according to the same law (Fig. 2). ${ }^{1} \mathrm{He}$ demonstrated that "emanation," i.e. radon, gives rise to a radioactive deposit on surfaces with which it is in contact. During this period Rutherford also studied the energy and penetrating power of the radiations emitted during the radioactive process.

\section{2-1903}

In collaboration with the young English chemist Frederick Soddy (Fig. 3), who was a demonstrator in Chemistry at McGill from 1900 to 1903 - although the partnership began only in October 1901 - Rutherford investigated the emanating power of thorium compounds and measured the rate of decay of the emanation (Fig, 4). ${ }^{2}$ (Thorium was much more readily obtained than radium.) Rutherford and Soddy studied the nature of radioactivity and in September/November 1902 enunciated the transformation theory of radioactivitity. ${ }^{3}$ This was a rad-

physics was an integral part of university programs in other fields, including medicine, engineering and chemistry. ical departure from the conviction that the atoms of each element are permanent and indestructible (indeed, the word atom means indivisible). During this period Rutherford showed that the $\alpha$-rays are actually heavy, positively-charged particles, although their precise nature was not elucidated until 1907$08 .^{4}$

\section{3-1905}

In this period Rutherford studied the succession of changes which constitute the radioactive series, whereby uranium is transformed via radium, into lead. In collaboration with his colleague Howard Barnes, Rutherford measured the energy associated with radioactive transformations ${ }^{5}$ and - with another colleague, Arthur Steward Eve - the nature of the gamma rays.

\section{$1905-1907$}

Rutherford's main study during this period was the nature and properties of the alpha-particle. ${ }^{6}$ By this time he had acquired a small research group; members of which investigated the radioactivity of the earth and the atmosphere, and made a detailed study of the radioactive series by chemical separation and physical measurements.

\section{Rutherford and the Curies}

Rutherford was not, of course, the only pioneer in the field of radioactivity. The other outstanding scientists were the Curies, Pierre and Marie, but their contribution was of a somewhat different nature: they were mainly concerned with the isolation and identification of the radioactive elements, including radium and polonium, whereas Rutherford was interested in the nature and mechanism of radioactivity. Rutherford met the Curies first in 1903 and, after Pierre's tragic death in 1906, Rutherford interacted with Marie on several occasions and assumed the role of "a calm, gentle, supportive friend, almost fatherly, although he was four years her junior."7 
Figure 6. Apparatus used by RutherFord and Barnes in $1904^{4}$ to measure the energy (heat) generated per second by a known mass of radioactive material.
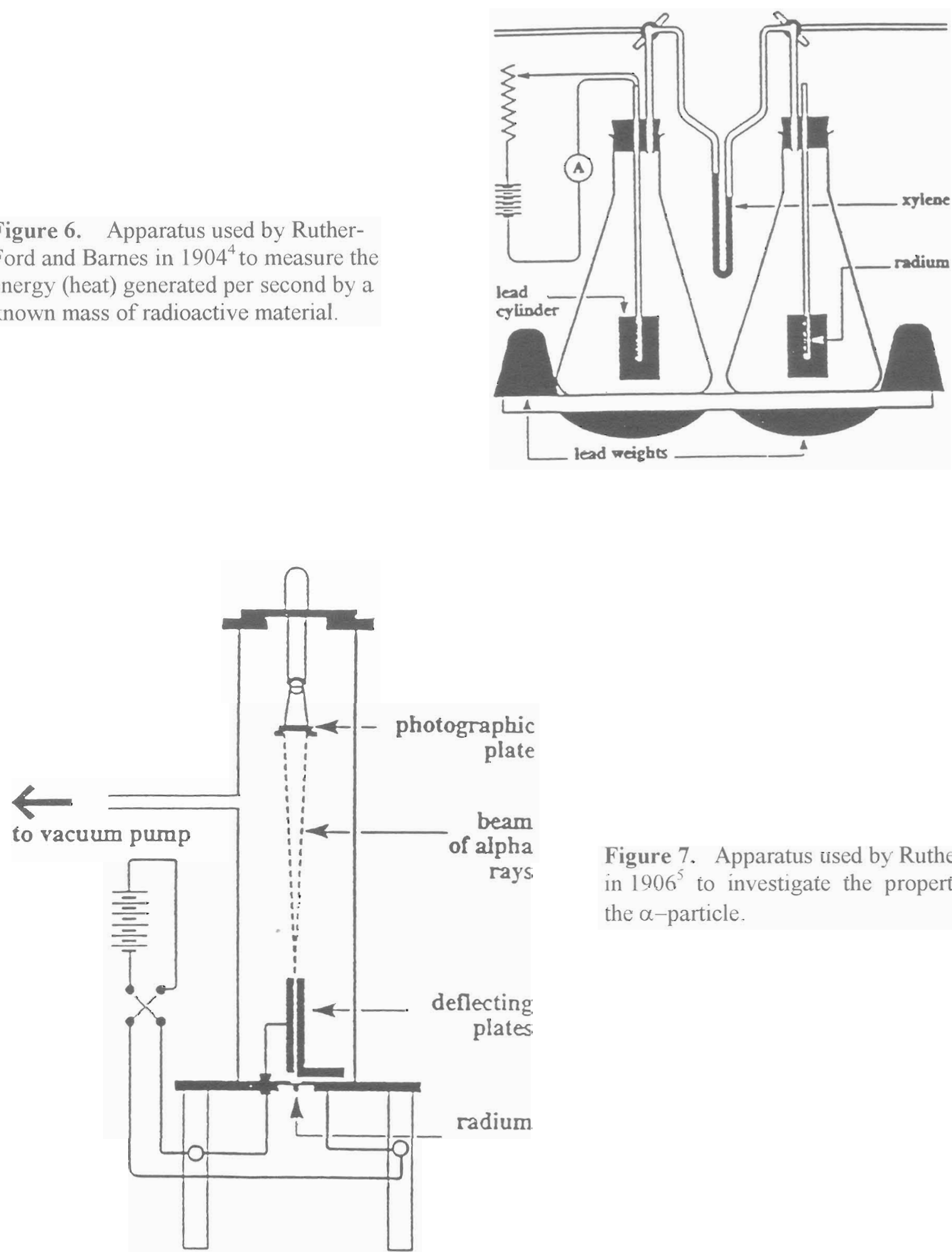

Figure 7. Apparatus used by Rutherford in $1906^{5}$ to investigate the properties of the $\alpha$-particle. 


\section{Rutherford leaves McGill}

In 1907 Rutherford was offered, and accepted, the post of Longworth Professor of Physics at Manchester University in England. In 1908 he was awarded a Nobel Prize (in Chemistry, not Physics) for his "investigations into the disintegration of elements and the chemistry of radioactive substances." Rutherford commented informally that he had observed many transformations with various time periods, but none quite as fast as his own from physicist to chemist! Although Rutherford was no longer at McGill, the research for which the prize was awarded was carried out in Montreal and we are justified in claiming him as McGill's Nobel Laureate.

Rutherford remained at Manchester until 1919, when he was appointed Cavendish Professor of Physics at Cambridge, a post he held until his death in 1937. Although he carried out, or supervised, important research at Manchester and Cambridge, including the development of the nuclear model of the atom in 1911-13, there is no doubt that his most productive period was that at McGill. It can be said, without exaggeration, that Rutherford's research at McGill laid the foundation of 20th century physical science.

\section{The Rutherford Museum}

In the period of Rutherford's work at McGill, scientific apparatus was usually fairly simple in design - although by no means simplistic in concept - and was constructed in the machine shop located in the Physics building. At the end of the investigation the apparatus was returned to the workshop, where it would be dismantled so that many of the components could be re-used in subsequent apparatus. This was the case with Rutherford's apparatus until 1900, when his colleague Howard Barnes pointed out that Rutherford was a pioneer in a new field of science and was already world-famous; it would be a crime against posterity to destroy his apparatus. The equipment was therefore put away in a cupboard where it remained, undisturbed, until the late 1930s.
After Rutherford's death, in 1937, his friend and former colleague, Arthur Stewart Eve, was asked by the Royal Society to write the "official" biography. For this purpose photographs of the apparatus were taken and the idea of a museum was born. The concept lay dormant until 1950, when Dr. Ferdinand Terroux, a lecturer (subsequently Professor) in Physics at McGill made a formal proposal to Dr. Norman Shaw, the Chairman of the Physics Department, for the construction of a "Rutherford $\mathrm{Mu}$ seum and Conference Room." However, no progress was made until 1964, when Dr. Shaw bequeathed $\$ 2,000$ to establish the Museum and an additional sum was provided by the McGill Graduates' Society. A room was allocated in the Macdonald Physics Building and Dr. Terroux undertook the laborious work of repairing, cleaning and renovating the items, while Dr. Terroux's architect son prepared the display graphics. The Museum was opened in October 1967.

\section{Acknowledgement}

By kind permission of Multimed Inc., and the Editors of Current Oncology, this article is published simultaneously in Volume 5 (1998) of the journal Current Oncology.

\section{Notes}

N.B. The papers listed below are only a small fraction of Rutherford's publications during his 9-year tenure at McGill. The full list comprises 51 full papers plus 19 short notes and letters to Nature, totalling over 750 pages of print.

1. Rutherford, E. A radioactive substance emitted from thorium compounds. Phil Mag 1900; ser. 5, 49: $1-14$.

2. Rutherford, E. and Soddy, F. The radioactivity of thorium compounds. Part I. An investigation of 
the radioactive emanation. Trans Chem Soc 1902; 81: 321-350.

3. Rutherford, E. and Soddy, F. The cause and nature of radioactivity. Phil Mag 1902; ser. 6, 4: 370-396 and 569-585.

4. Rutherford, E. The magnetic and electric deviation of the easily absorbed rays from radium. Phil Mag 1903; ser. 6, 5: 177-187.

5. Rutherford, E. and Barnes, H.T. Heating effect of the radium emanation. Phil Mag 1904; ser. 6, 7: 202-219.

6. Rutherford, E. The mass and velocity of the $\alpha$ particles expelled from radium and actinium. Phil Mag 1906; ser. 6, 12: 348-371.

7. Wilson, D. Rutherford. A Simple Genius. Cambridge, MA: MIT Press, 1983; 254.

\section{Bibliography}

Rutherford. Being the Life and Letters of the Rt. Hon. Lord Rutherford, O.M., by A.S. Eve (Cambridge Univ. Press, 1939.)

Lord Rutherford, by Norman Feather. (Priory Press, 1940.)

Rutherford - Recollections of the Cambridge Days, by Mark Oliphant. (Elsevier Publishing Co., Amsterdam and London, 1972.)

The Self-Splitting Atom. A History of the Rutherford-Soddy Collaboration, by Thaddeus J. Trenn. (Taylor and Francis, London, 1977.)

Rutherford and Physics at the Turn of the Century, edited by Mario Bunge and William R. Shea (Dawsun and Science History Publications, New York, 1979.)
Rutherford. Simple Genius, by David Wilson. (M.I.T. Press, Cambridge, Mass., 1983.)

Ernest Rutherford, in Radiological Physicists, by Juan A. del Regato, pp. 37-49 (American Inst. of Physics, New York, 1985.)

My Dear Eve...The Letters of Ernest Rutherford to Arthur Stewart Eve, by Montague Cohen. Fontanus, 1, 3-37 (1988); 2, 111-138 (1989); 느, 69108 (1991); $\underline{5}, 123-159$ (1992).

Rutherford's Curriculum Vitae, 1894-1907, by Montague Cohen. Medical Physics, 22, 841-859 (1995).

Ernest Rutherford and Frederic Soddy: An Historic Partnership, by Montague Cohen. The Chemical Intelligencer, April 1997, 33-40 (Springer-Verlag, New York.)

Rutherford and Soddy: The Cause and Nature of Radioactivity, by Montague Cohen. Ceramic Transactions, 87, 149-158 (1998). 